\title{
3D PHOTOGRAPHS IN CULTURAL HERITAGE
}

\author{
W.Schuhr ${ }^{\mathrm{a}, *}$, J.D. Lee ${ }^{\mathrm{b}}$, St.Kiel ${ }^{\mathrm{a}}$

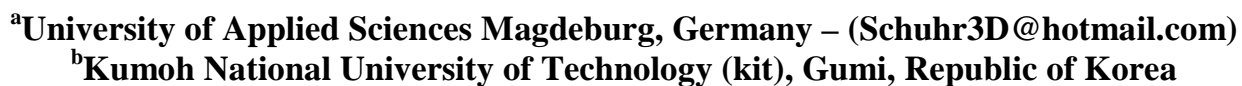 \\ XXIV $^{\text {th }}$ CIPA International Symposium, 2-6 September 2013, INSA Strasbourg (France)
}

KEY WORDS: Cultural Heritage, History, Internet/Web, Human Settlement, Technology

\begin{abstract}
:
This paper on providing "oo-information" (= objective object-information) on cultural monuments and sites, based on 3D photographs is also a contribution of CIPA task group 3 to the 2013 CIPA Symposium in Strasbourg.

To stimulate the interest in 3D photography for scientists as well as for amateurs, 3D-Masterpieces are presented.

Exemplary it is shown, due to their high documentary value ("near reality"), 3D photography support, e.g. the recording, the visualization, the interpretation, the preservation and the restoration of architectural and archaeological objects. This also includes samples for excavation documentation, 3D coordinate calculation, 3D photographs applied for virtual museum purposes and as educational tools. In addition 3D photography is used for virtual museum purposes, as well as an educational tool and for spatial structure enhancement, which in particular holds for inscriptions and in rock arts.

This paper is also an invitation to participate in a systematic survey on existing international archives of 3D photographs. In this respect it is also reported on first results, to define an optimum digitization rate for analog stereo views.

It is more than overdue, in addition to the access to international archives for 3D photography, the available 3D photography data should appear in a global GIS(cloud)-system, like on, e.g., google earth.

This contribution also deals with exposing new 3D photographs to document monuments of importance for Cultural Heritage, including the use of 3D and single lense cameras from a $10 \mathrm{~m}$ telescope staff, to be used for extremely low earth based airborne 3D photography, as well as for "underwater staff photography". In addition it is reported on the use of captive balloon and drone platforms for 3D photography in Cultural Heritage.

It is liked to emphasize, the still underestimated 3D effect on real objects even allows, e.g., the spatial perception of extremely small scratches as well as of nuances in color differences.

Though 3D photographs are a well established basic photographic and photogrammetric tool, they are still a matter of research and practical improvement:

- For example, multistage concepts for 3D heritage photographs, e.g., combining before and aft images and images showing different focus, daytime etc., as well as combining 3D imagery of different sensors and comparing 3D imagery with drawings etc. and even standards for exposing and processing 3D heritage photographs are only some topics for recent research.

- To advise on state-of-the-art 3D visualisation methodology for Cultural heritage purposes an updated synoptically overview, even claiming completeness, also will be dealt with.

- 3D photographs increasingly should replace old fashioned subjective interpreted manual 2D drawings (in 2D only) of heritage monuments.

- Currently we are witnesses of early developments, showing Cultural Heritage objects in 3D crystal as well as in 3D printings.
\end{abstract}

\section{INTRODUCTION}

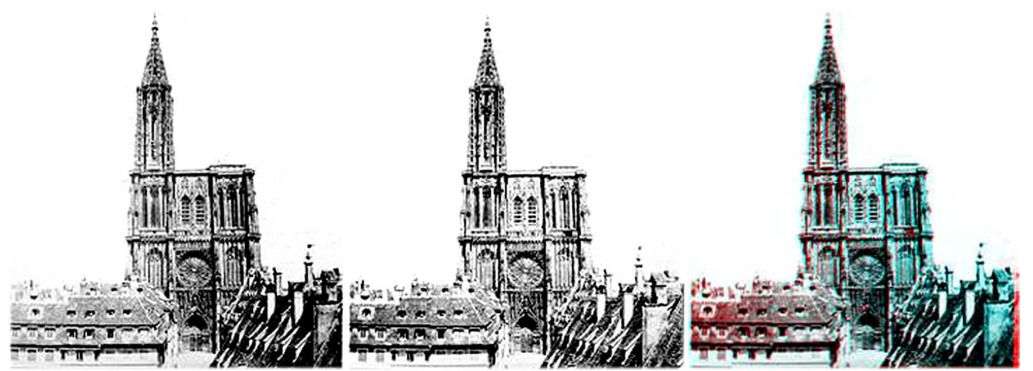

Figure 1. As homage to the XXIVth international CIPA Symposium in Strasbourg, a historic stereo view of the famous Strasbourg Cathedral, dated approximately 1860 is shown beside the 3D color anaglyphs presentation (use color anaglyph glasses, repro photography by W. Schuhr)

This paper of CIPA task group 3 is on providing quasi objective information on cultural monuments and sites, based on 3D photographs. This exemplarily shall be proved by the masterpieces presented, which also shall stimulate the interest in 3D photography for scientists as well as for amateurs.
Due to their high documentary value ("near reality"), 3D photographs support, e.g. the recording, the visualization, the preservation and the restoration of architectural and archaeological objects, including excavation documentation, 
virtual museum requirements, spatial structure enhancements for, e.g., inscriptions etc. (see Figures 8 and 9).

\section{OBJECTIVES}

Though 3D photographs are a well established basic photographic and photogrammetric tool, they are still a matter of research and practical improvement:

\subsection{Objectives regarding existing 3D photography in- Cultural Heritage}

- This paper is also an invitation to participate in a systematic survey on existing international archives of 3D photographs - and to define an optimum digitization rate for (existing) analog stereo views.

\subsection{Objectives regarding the exposure of new 3D} photography in Cultural Heritage

- This contribution also deals with exposing new 3D photographs to document monuments of importance for Cultural Heritage, including the use of 3D cameras as well as the use of single lense cameras from a $10 \mathrm{~m}$ telescope staff, to achieve extremely low earth based airborne 3D photography, as well as for "underwater staff photography".

- In addition it is reported on the use of captive balloon and drone platforms for 3D photography in Cultural Heritage.

- Another objective is to define standards for exposing and processing $3 \mathrm{D}$ heritage photographs.

2.3 Objectives regarding existing and new 3D photography in Cultural Heritage

- The benefit of multistage concepts for 3D heritage photographs, e.g., of combining before and aft images and images showing different focus, daytime etc., as well as of combining 3D imagery of different sensors and comparing 3D imagery with drawings etc. shall also be investigated.

\subsection{Objectives regarding 3D visualization Techniques in Cultural Heritage}

- To advise on state-of-the-art 3D visualisation methodology for Cultural heritage purposes an updated synoptical overview, even claiming completeness (!), also will be dealt with.

- Currently we are witnesses of early developments showing Cultural Heritage objects in 3D in crystal and/or as 3D prints ("like in the early days of the invention of photography").

\section{Methods Applied}

\subsection{Methods applied regarding existing 3D photography}

survey on international archives of existing analog and digital 3D photography

- $\quad$ Applying and improving the processing to present masterpieces of existing 3D photography, including first results, to define an optimum digitization rate for analog stereo views

3.2 Methods applied regarding the exposure of new 3D photographs

applying XLITE carbon telescope staff 3D photography from approximately $13 \mathrm{~m}$ height using single lense cameras. The camera recently used is a $3^{\text {rd }}$ generation SONY NEX-5R system camera. This camera shows WLAN capability and allows smart-phone(App) based remote control, as carried out by Stephan KIEL of the University of Applied Sciences in Magdeburg (see Fig. 2)

using 3D cameras, like, e.g., a combination of 2 (or more) synchronized single lense cameras with remote ground(see Figure 3) and/or the Fuji Fine Pix REAL 3D W3 etc.

comparison of 3D imagery with 2D photographs and with (current) drawings of the same heritage object (see Figures $9 \&$ 10)

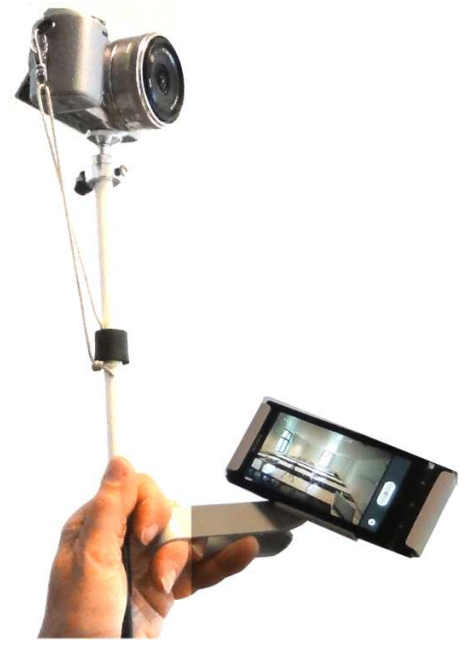

Figure 2. XLITE telescope staff with $3^{\text {rd }}$ generation SONY NEX-5R system camera WLAN capable camera with smartphone(App) based remote control

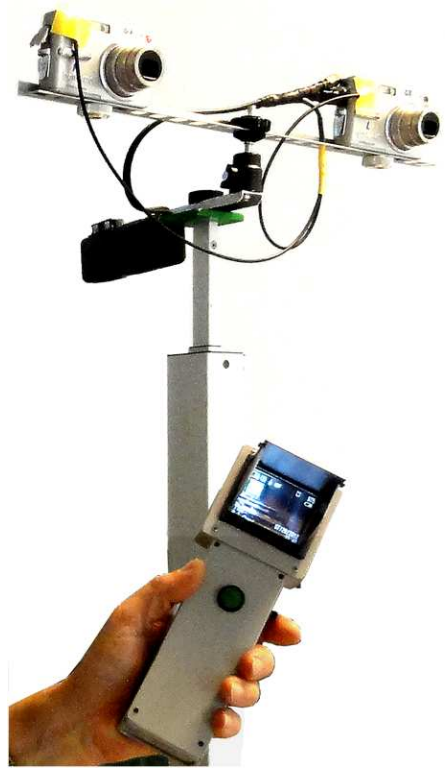

Figure 3. $2^{\text {nd }}$ generation Alu telescope staff $3 \mathrm{D}$ camera

\subsection{A systematic survey of real and virtual 3D visualization principles}

even claiming completeness, successfully has been improved (see Table 1).

4. RESULTS 


\subsection{Results regarding existing 3D photography:}

The historic 3D masterpiece of the Eiffel Tower of Paris (see Figure 4) represents huge archives of international 3D photography (see also Figure 11), like, e.g., the famous Keystone-Mast collection of the California Museum of Photography (CMP, see Figure 5):

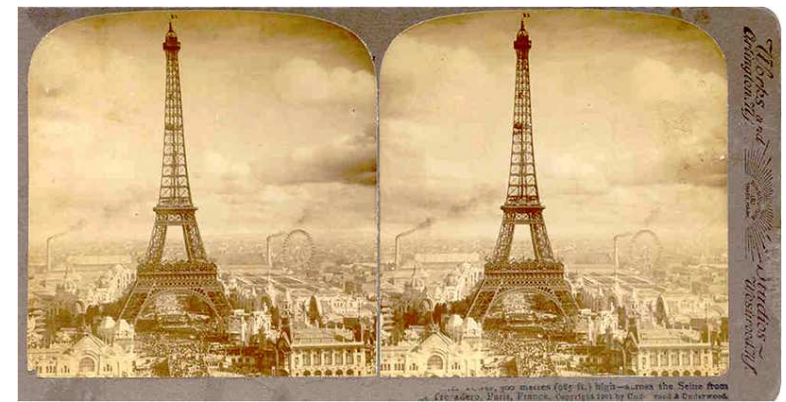

Figure 4. Outstanding historic 3D photograph of the Eiffel tower of importance for Cultural Heritage, by Underwood and Underwood, dating 1901 (reproduction by W. Schuhr)

The CMP in total owns unbelievable more than 2 Million analog stereo negatives and stereo prints, including the complete stereo view collections of the famous companies Keystone, Underwood and Underwood and Whites. In cooperation with the University of California Riverside (UCR) the CMP runs an online archive of international 3D photographs, including the work of the famous historic photographers George Lewis, F. White, Harry L. Sanders, J. C. Sawders, B. L. Singley etc..Beside others namely Timothy Klein on http://www.ibiblio.org/pub/multimedia/3d/3dphoto/3d.prod.serv gives a list of additional approximately 200 $3 \mathrm{D}$ agencies, mainly dealing with 3D photography, see also Waldsmith (2002). Also to name is Ammatzia Peled's collection of color anaglyphs of Cultural Heritage in Israel, showing outstanding quality, see http://www.rjb-3d.com/ In addition the authors posses some 1000 heritage stereo views, mainly unicats.

It is liked to emphasize, beside an improved list of international existing archives, it is highly recommended, to digitize and to document every particular 3D photograph with its object description, position, viewing direction, date, camera- and film data, photographer and access information in a global GIS system, like in "3D photographs on google earth".

In addition to the access to international archives for 3D photography, the available 3D photography completely should appear on a global GIS-system, like on, e.g., google earth, showing the positions, the shooting direction and the type of the stereo partner, for which first steps have been carried out by KONICA at the ISPRS congress in Vienna in 1996 already.

First results of the interpretation of 3D photography showing the same objects but different resolution for 9 by 9 inch photography, for the digitization rate of analog 3D photography lead to a minimum requirement of about $50 \mu \mathrm{m}$ pixel size, which is equivalent to $500 \mathrm{dpi}$ or approximately $4500 \times 4500$ pixels per 9 by 9inch frame or 1400 x 1400 pixels for standard 7 x $7 \mathrm{~cm}$ stereo views, see also Schuhr et.al.(2012).

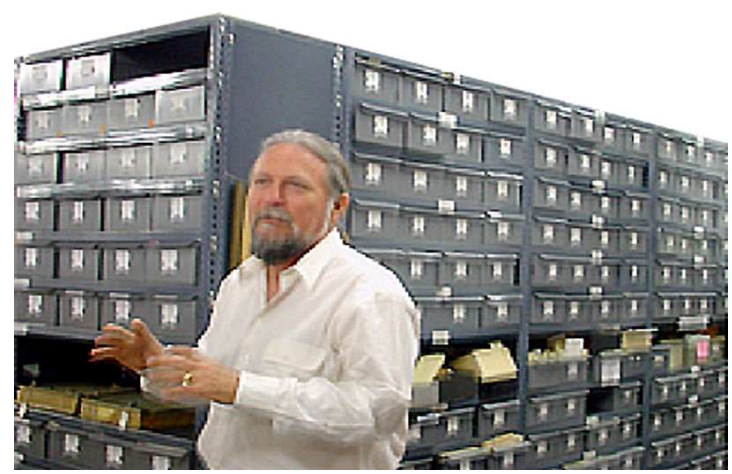

Figure 5. Inside the Keystone-Mast Collection, carrying approximately 350000 original glass slides of international historic 3D photography; Steve Thomas, head of the CMP in Los Angeles (USA) in front of his treasure chest, partly still waiting for excavation (photography by F.LeBlanc/GCI)

Applied methods regarding exposing new 3D photographs

The authors doubt, there is a universal formula, to calculate the (one and only) optimum base length, because the expectation criteria for 3D imagery individually vary from "insisting in true 3D perception" until "extremely enhanced 3D perception". From that point of view a stereo camera, like, e.g., the Fuji Fine Pix Real 3D with fixed base length only shows a limited spatial range. Therefore, in case of using single lense cameras, the authors highly recommend taking not just 2 stereo photographs but to take a queue of about 5 photographs with different base lengths, which allows post processing's according to different requirements, see Figures 3 and 6 as well as Schuhr et al. (2000 and 2005)

Very recently $3 \mathrm{D}$ photographs were taken from a $13 \mathrm{~m}$ XLITE carbon telescope staff, using a $3^{\text {rd }}$ generation SONY NEX-5R system camera WLAN capable camera with smart-phone(App) based remote control (see Figure 2).

The use of a telescope staff camera is also suited to take under water $3 \mathrm{D}$ photographs.

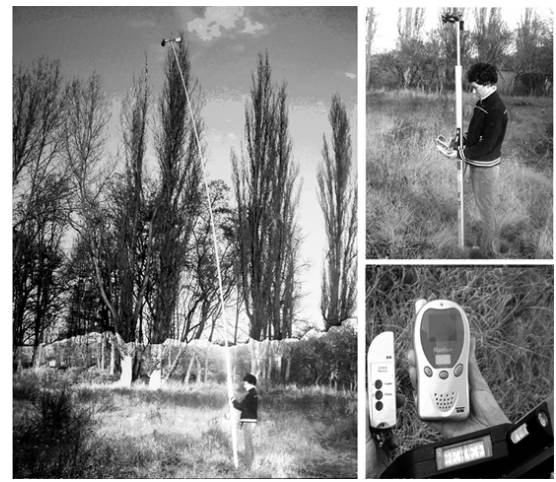

Figure 6. $2^{\text {nd }}$ generation exposures of airborne aerial 3D photographs showing extremely high resolution, using a $10 \mathrm{~m}$ telescope staff (photography by Katja Silz)

Currently 3D photographs in Cultural Heritage based on civil drones like,e.g., in Fig.7, seem to promise a great future.

Though these drones carry on board GPS and allow a programming of the course, including emergency reactions, it is liked to advice, due to extremely high risks, drones should be operated by skilled personal only. 


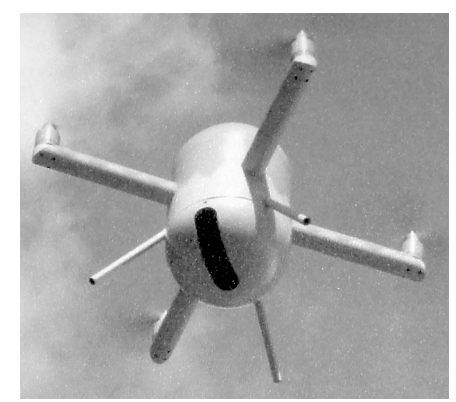

Figure 7. Advanced ground steered civil drone (courtesy Air Force Institute of Technology, Warsaw (Poland)

\subsection{Samples for new masterpieces of 3D photography}

are shown in Figures 8 until 12 as well as in Figure 15.

3D photographs aid the interpretation (see Figure 4, 8, 9, 10 and $15)$ and the processing of $3 \mathrm{D}$ coordinates, but also serve as an educational tool (see Figure 4, 8, 9, 10 and 15).

It is liked to emphasize, the still underestimated 3D effect, also superior to a manual drawing, even allows, e.g., the spatial perception of extremely small scratches on a real object, as well as of nuances in color differences (e.g. in Figure 9 and 10).

It is more than overdue, 3D photographs increasingly should replace out of date and time wasting subjective interpreted manual 2D drawings of heritage monuments (e.g. in Figure 9 and see also Waldhaeusl and Ogleby (1994)). In this context also the use of so called field pantographs in particular should be stopped immediately, as they can easy be replaced even by conventional single photography in combination with image rectification based on routine processing, including simple ground control measurement, see also Schuhr et al. (2008)

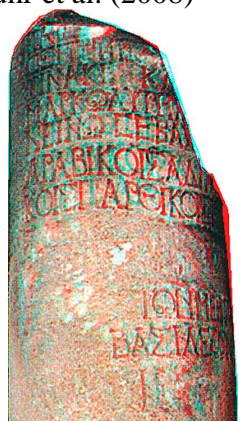

Figure 8. 3D Photogr.of an antique column in Patara (Turkey) allows an enhancement of inscriptions (Photogr. by Schuhr)

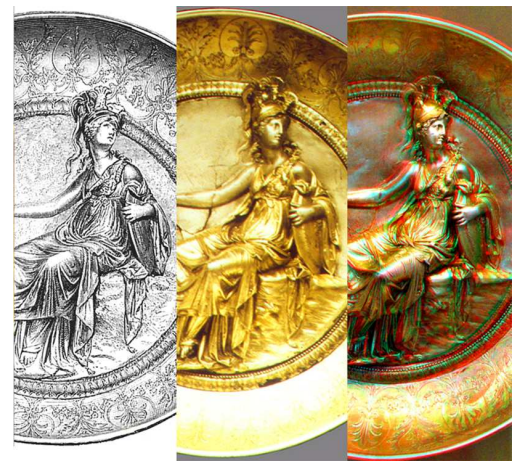

Figure 9. The comparison of a manual drawing with a $2 \mathrm{D}$ photography and a color anaglyphs presentation of a part of the Athena dish of the famous Hildesheim Treasure clearly indicates the objectivity of the 3D photography and gives reason to skip the manual drawing totally (photograph by W. Schuhr)

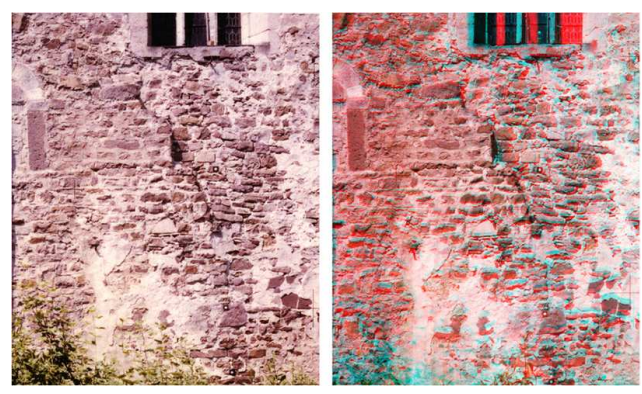

Figure 10. Comparison of a 2D photograph with a 3D image of the same heritage object (Monastery Bursfelde, Germany, photograph by Walter Schuhr)

4.4 A systematic survey of real and virtual 3D visualization principles

To advise on state-of-the-art 3D visualization methodology for Cultural heritage purposes an updated synoptically overview, even claiming completeness, is dealt with in Table 1 (compare also Schuhr et al. (2002):

\begin{tabular}{|l|}
\hline * VIRTUAL 3D VISUALIZATION PRINCIPLES: \\
\hline 1) 3D perception of in minimum 2 stereo mates, projected without \\
contact for ortho, pseudo, for normal and/or cross 3D \\
visualization: AUTO STEREOSCOPIC VIEW(see Figure 1, 2, 5 \& 10), \\
MAGIC EYE/ RANDOM DOT, HEAD MOUNTED DISPLAY, \\
STEREOSCOPES: LENS STEREOSCOPES and/or MIRROR \\
STEREOSCOPES (e.g.: Wheatstone), vertical mirror: PIGEON; \\
horizontal mirror: DOWN UNDER, PRISM STEREOSCOPES \\
(horiz.stereo mates; (vertical: KMQ),, LENTICULAR LENSES (3D \\
POSTCARDS), STRIP BARRIER \\
\hline 2)Stereo mates projected in contact, using alternate projection \\
and/or different color via (COLOR-) ANAGLYPHS (compare Figure \\
11,12 \& 17), DOLBY IN(TERFERENCE) FI(LTER)-TEC(HNOLOGY): \\
multiplexing \& interference filter glasSes, CROMA-DEPTHS \\
(spectral color separation),POLARIZING FILTER TECHN., (Liquid \\
Crystal)SHUTTER GLASSES, NuOptiX(PULFRICH: 3D \\
movies\&CYBER SPACE) \\
\hline 3) 3D perception Techniques Using VIRTUAL 3D MODELS: \\
MIRRORS, 3D Rotating (FELIX 3D) or OSCillating (BOLLOGRAPH) \\
Screen or (FELIX) 3D SOLID STATE SCREEN (a new 3D Computer \\
Screen generation? See Figure 14), HOLOGRAM Technologies \\
\hline *REALITY \& REAL MODELS (see Figure 16) including lasered \\
crystals (compare Figures 11,12,14 and 15)
\end{tabular}

Table 1. 3D visualization methods - the complete list -(status: XXIVth international CIPA Symposium,Strasbourg, September 2013)

Though Table 1 is claiming completeness in stating 3D visualization Techniques, reports on missing 3D principles are very welcome. A consequent dealing with 3D Technology according to Table 1 , even might indicate the very beginning of new age of "real" $3 \mathrm{D}$-PC-screens, at least partly replacing "old fashioned" 2D-PC-screens. A first sample for this paradigm change from 2D into 3D PC screen technology is the FELIX solid state prototype. Here the spatial visualization of 3D image data already works without any glasses, see Schuhr et al. (2010).

In this respect today's lasered crystals (see Fig. $11 \& 12$ ) are also identified as "early bird" 3D products, though, due to lack in resolution, contrast and color, their current level of development might even still remember to the stage of the invention of the photography by Niepce in 1827 (see Figure 13 and Gernsheim (1965)). 


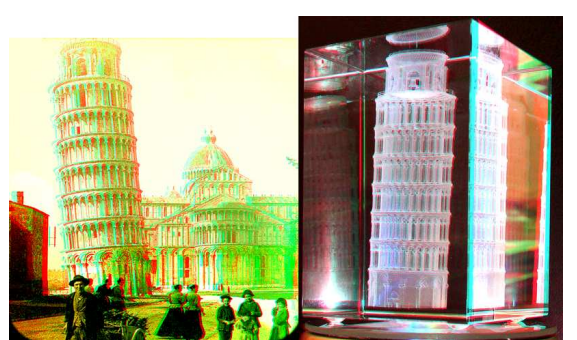

Figure 11. Historic Photographic Keystone masterpiece in 3D of the Leaning Tower of Pisa (Italy) in comparison with color anaglyphs presentation of an "early bird" lasered crystal (anaglyphs by W. Schuhr; lasered crystal: courtesy R.Titze of LOOXIS, Hannover)
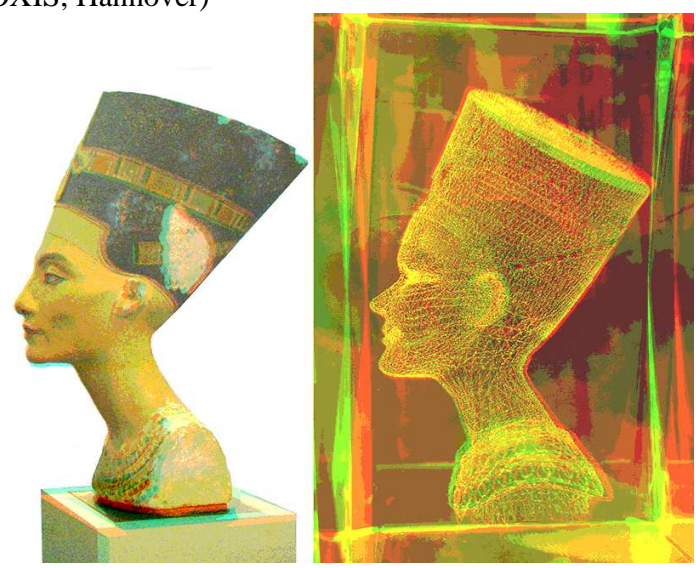

Figure 12. Color anaglyphs of the famous bust of Nofretete from Tell el-Amarna (Egypt) (nowadays in Berlin, Germany) showing extreme high resolution, in comparison with a "zero generation" lasered crystal of the same object, currently lacking resolution and radiometric significance.

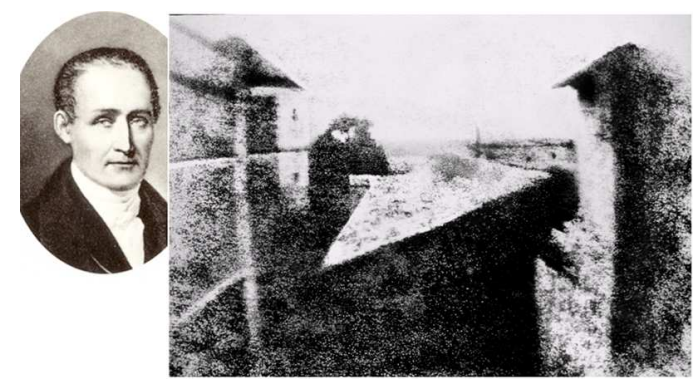

Figure 13. The well known 1st handed down photography (from approx. 1826) of Joseph Nicéphore Niépce, the inventor of photography, showing the pigeon roof through a window of his house in Saint-Loup-de-Varenne (France) (retouche initiated by Gernsheim (1965))

Lasered crystals already became part of our daily life and might mark the first step of an expected booming progress in advanced 3D Visualization (not only) of Cultural Heritage.

Typical technical data for laser engraving devices are:

- Maximum volume of glass bodies: 2,2 x 3,2 x 0,2 m

- typical crystal bodies $50 \times 50 \times 80 \mathrm{~mm}$

- object size/duration: 225000 points/ 1 to 3 minutes

- point size $50 \mu \mathrm{m}$

- repeating accuracy in $\mathrm{x}$ and $\mathrm{y}: \pm 5 \mu \mathrm{m}$

- drive: step motor or linear motor $(\mathrm{x}, \mathrm{y})$, servomotor $(\mathrm{z})$
To stimulate the crystal structure no forward intersection of 2 laser beams is necessary, but the point by point lasering of the crystal is verified by using just one laser beam with proper permanent changing in focus.

A crystal, once lasered, later on still allows a continuation and/or an adding of other lasered objects. But to delete lasered information in crystal is not yet possibly, but a matter of (feverish!) international research. A crystal, which allows repeated lasering and deleting, of course, would be one very important step for a new 3D screen generation.

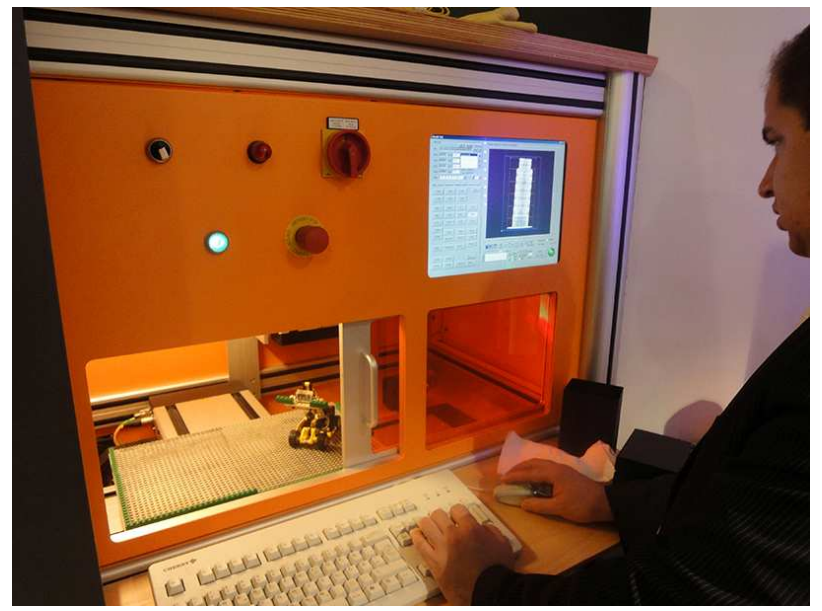

Figure 14. VITRO crystal laser engraving machine of company LOOXIS (Hannover, Germany) obviously currently pushing the 3D Technology in Cultural heritage (courtesy R.Titze, Hannover; similar: CERION)

Furthermore lasered crystals even allow quasi freezing of moments of dynamic processes in 3D (e.g. in Figure 15)

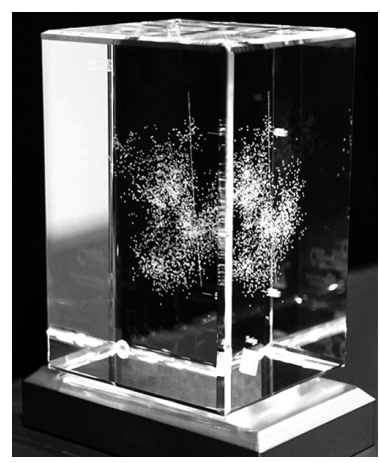

Figure 15. Principle sample for 3D data with relevance for cultural heritage: Seismic activity preserved in crystal (courtesy R.Titze/LOOXIS (Hannover, Germany), sample modified by W. Schuhr)

Of course real models also belong to the principals of 3D visualization (see Figure 16). 


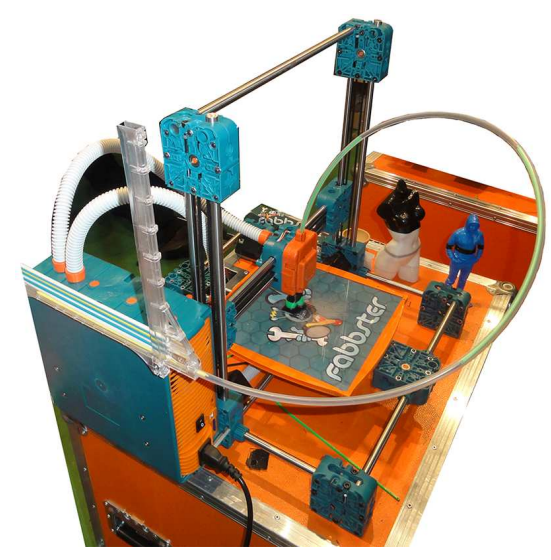

Figure 16. Sample of a 3D printer suited to print, e.g., 3D models of Cultural Heritage objects with maximum size of $225 \mathrm{~mm} \times 225 \mathrm{~mm} \times 210 \mathrm{~mm}$ showing $\pm 0.1 \mathrm{~mm}$ (Fabbster $3 \mathrm{D}$ printer, courtesy Sintermask Company (Germany); photograph by W.Schuhr)

\section{CONCLUSIONS}

Summarizing, remaining important steps, for the application of 3D photographs in Cultural Heritage beside others are

-to improve heritage 3D photography recording and documentation, including improvements in digitization of existing stereo views

-to improve the web site "3dsite.icomos.org" of CIPA TG 3 on "3D photographs in Cultural Heritage" with respect to samples, visualization and applications for heritage documentation, protection and reconstruction purposes

-to recommend low-cost software to prepare state of the art heritage stereo view presentations, e.g. as color anaglyphs and to extract metric information from the stereo images

-"Digging the treasure" of rare, unknown or even lost 3D photographs in the field of Cultural heritage are seen as a permanent task

-In addition to the access to international archives for $3 \mathrm{D}$ photography, the available 3D photography should appear in a global GIS-system, like on, e.g., google earth. It is highly recommended, to add the GPS coordinates and the camera orientation to every stereo pair, whenever possible. For camera positioning and orientation registration in caves, recently gyro systems appeared on the market.

-Currently 3D photography based on ground steered civil drones, carrying on board GPS promise a great future.

Though Table 1 is claiming completeness in stating 3D visualization Techniques, reports on missing 3D principles are welcome.

-A consequent dealing with 3D Technology according to Table 1 , might even witness the very beginning of new age of "real" solid state 3D-PC-screens.

\section{REMARKS}

The non-commercial archive of 3D photography, runned by the authors, provides and collects analog and digital 3D imagery from all over the world. I $f$ you are seeking for particular 3D photography or if you offer 3D imagery, kindly leave an email, see Figure 17.

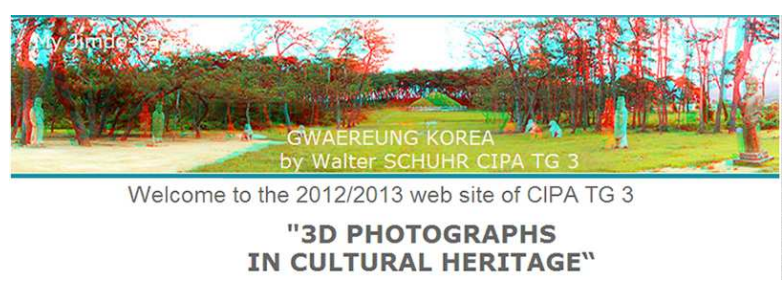

Figure 17. $1^{\text {st }}$ page of the web site www.3dphoto.jimdo.com of CIPA task group 3 on "3D photographs in Cultural Heritage"

\section{REFERENCES}

\section{References from Books:}

Gernsheim,H.and A., 1965. A Concise History of Photography. Crosset\& Dunlap,NY(USA)

Waldsmith, J., 2002. Stereo Views. Krause Publications; Library of Congr. Catalog Nr. 2001099523, $2^{\text {nd }}$ edition, Iola, Wisconsin(USA)

\section{References from Other Literature:}

Schuhr,W.and Kanngieser,E.,2000.Back to the Roots in Photogrammetry,Remote Sensing and GIS. In: The Internat. Archives of the Photogrammetry, Remote Sensing and Spatial Information Sciences, Amsterdam (NL)

Schuhr,W.and Kanngieser,E.,2002.3D Visualization Techniques-the Complete List. In: The Internat. Arch. of the Photogr., Remote Sensing and Spatial Information Sc., Comm.V Symp.Proceed. Corfu (Greece)

Schuhr,W.and Kanngieser,E.,2005. International Stereoviews to save the World's Cultural Heritage. In: CIPA Symp.Proceed.,Turin(Italy)

Schuhr,W.and Kanngieser,E.,2008. Recording, Document. and Applic. of Stereo Views in Cultural Heritage. In: The Internat. Arch. of Photogr., Remote Sensing and Spatial Inform. Sc., CommV Proceed.,Beijing (China)

Schuhr,W.and Kanngieser,E., 2010. 3D VISUALIZATION TECHNIQUES IN CARTOGRAPHY. In: $3^{\text {rd }}$ International Conference on Cartography and GIS, Nessebar (Bulgaria) Schuhr, W., Lee, J.-D. and Kanngieser, E., 2012. IMAGING A SUSTAINABLE FUTURE IN 3D. In: The Internat. Archives Photogr., Remote Sensing \& Spatial Inform. Sciences, pres. paper, ISPRS-Comm. V, Melbourne (Australia)

Waldhaeusl, P.and Ogleby, C., 1994. 3-by-3 Rules for Simple Photogrammetry. In: The Internat. Archives Photogr., Remote Sensing \& Spatial Inform. Sciences, ISPRS Comm. V Symp. Proceed., Melbourne (Australia) 